\title{
A Case Study of the Diachronic Development of Second Language Grammatical Competence Based on Computer-mediated Negotiated Interaction
}

\author{
Liping Jiang ${ }^{1,2, *}$ \\ ${ }^{1}$ School of Business and Foreign Studies, Guangdong Mechanical \&Electrical Polytechnic, Guangzhou, China \\ ${ }^{2}$ School of Social Sciences and Humanities, University College Sedaya International, Kuala Lumpur, Malaysia \\ Corresponding author.
}

\begin{abstract}
The emergence of computer-mediated real-time communication platform provides second language learners with the opportunity to communicate with the target language through the network. This empirical study is based on the English text-based data of online store learners in four periods of real-time online communication platform to explore the grammatical development of interlanguage of middle-level English learners in computer-mediated real-time interactive negotiation. Corpus analysis shows that learners' accuracy of L2 grammatical forms has been improved, with obvious changes in the first and second periods, but no significant changes in their grammatical competence in the later periods. The frequency of using compound sentences is low, and it shows a downward trend in the later stages. The research shows that computer-mediated real-time communication promotes learners' second language acquisition to a certain extent, but the communicative context and purpose affect its further improvement of interlanguage grammar.
\end{abstract}

Keywords: Computer-mediated negotiated interaction, Text-based Online chat, Second language acquisition, Interactive communication

\section{Introduction}

With the ongoing development of modern education and information technology, it is of great significance for foreign language teaching to carry out the research on the role of network communication interaction in second language acquisition. Researchers explore the role of interactive negotiation in the development of learners' second language competence from the perspective of text features of interactive negotiation based on computer network[1-5]. But so far, due to the difficulty of collecting diachronic data in real communication, few researchers have studied the influence and effect of computer-mediated interactive negotiation on intermediate level English learners' language production ability from the perspective of diachronic case. Foreign trade network communication platform enables online shop learners to have business talks with foreign English or non-English native customers in the virtual context of the network, carry out information exchange and interaction, complete the real communication task, and realize the communication interaction based on computer -mediated text. This network real-time interactive context provides a good vision for the study of the relationship between real-time computer text communication and second language acquisition, and the role of interactive negotiation in the development of adult learners' interlanguage.

\section{Literature review}

2.1 Computer-mediated real-time text communication

Computer-mediated real-time text communication is a form of two-way real-time communication by using text as

ISSN: 0010-8189

(C) CONVERTER 2020

www.converter-magazine.info 
the media. Its discourse features are very similar to face-to-face oral communication, and it is an interactive real-time writing form in the real-time sense. The unique feature of "chatting" is that it combines the characteristics of speaking and writing [6]. Due to the "login" function of most computer communication programs, researchers can easily obtain these interactive corpus for research and teaching. Compared with the traditional face-to-face recording process, computer-mediated text data processing is not easy to disturb students [7]. Therefore, the sampling of online chat text is convenient, real and objective, and chatters will not misunderstand each other because of different accents or unclear listening. These features of computer real-time text communication provide conditions for studying the role of interactive negotiation in second language development.

Some studies have shown that computer-mediated text communication is suitable for the development of second language. It is believed that real-time text communication enables learners to avoid the limitation of memory, have more thinking time and opportunities [8], reflect on the output content [9]. As an embedded external memory assistant, text form makes learners more aware of the modified input in interaction, which is helpful to memory [10]. Beauvois believes that real-time communication context based on text can promote better language acquisition, because in the text-based online communication, learners' anxiety is low, their willingness to participate is high, they cooperate to construct knowledge, and they build learning communities more frankly [11].

Many researchers believe that the interactive negotiation characteristics of online chatting promote learners' language acquisition in real-time computer network communication. Salaberry discusses the supporting features and power relations of network context, and believes that it provides learners with a good environment to pay attention to the gap between their own interlanguage and target language in interactive negotiation [12]. Pellettieri examined the possibility of promoting second language acquisition by analyzing the negotiating steps of real-time text-based online chat, believing that it promotes interactive negotiation and arouses learners to pay attention to the problems in their own language [13].

\subsection{Interaction theory}

The experience of learning mother tongue shows that interactive communication in context is an ideal environment for language learning. Researchers at home and abroad began to study the role of interaction in the cultivation of second language competence earlier. The interaction hypothesis holds that in the process of meaning negotiation, especially the interaction with native language or better language chatters, learners can promote language acquisition[14]. Interaction links language input, learners' internal competence (especially selective attention) and diverse language output. Smith holds that learners achieve second language acquisition when they solve communication problems through conversation modification or meaning negotiation [15]. Negotiation guides learners to pay attention to the gap between the target language and their own interlanguage, so as to pay attention to the unclear or unknown information in the target language and acquire it in negotiation. Negotiation provides the first step in language learning and acts as a "starter" [16].

Ellis holds that in the conversation between non-native speakers or between non-native speakers and native speakers, interpretation creates an ideal condition for the target mother language to get access to [17]. The process of information clarification in interactive negotiation, on the one hand, provides learners with the opportunity to pay attention to the language, on the other hand, gives the chatters the opportunity to adjust the language, so that learners can understand the input content [18]. Interactive negotiation can help learners use their processing ability, pay attention to the language adjustment and input form of the other party, and absorb the structure of the target language in their own interlanguage. Negotiation process enables learners to produce output, verify the hypothesis of target language grammar, refine language output according to feedback and correction, and enhance acquisition [19].

\section{Research design}

ISSN: 0010-8189 


\subsection{Research objects}

The research object is a 23-year-old male learner engaged in foreign trade online communication, who carries out online trade negotiations in English throughout the data collection period. The learner's English is in the early stage of intermediate level. In December 2018, he began to communicate with foreign customers in English and conclude transactions. During the data collection period, learners are exempt from English class and do not participate in English learning and training. Therefore, the online corpus can truly reflect the role of computer-mediated real-time text communication in the development of interlanguage.

\subsection{Research data}

The research data is the real corpus of real-time text-based communication between online shop learners (hereinafter referred to as learners) and foreign customers on the foreign trade network exchange platform. It is the text of real-time computer communication in the period of one year and nine months from December 2018 to September 2020, and four periods: December 2018, September 2019, September 2020, The corpus of March 2020 and September 2020. Take 5 complete trading dialogues in each period, with a total of 20 online chat texts. The text dialogue mainly focuses on four links: product ordering, price negotiation, goods delivery and sales feedback, which is the language corpus of natural communication. Learners are business practitioners who want to get a deal. They have clear goals and positive motives. Therefore, the corpus can be regarded as a representative sample of real interaction.

\subsection{Research questions}

The purpose of this study is to explore the development and change of L2 grammatical competence of intermediate level online shop learners in the process of computer-mediated interactive negotiation, mainly focusing on two questions: (1) How does the morphological accuracy of students' interlanguage change? (2) How does the syntactic complexity of students' interlanguage change?

\subsection{Research methods}

Quantitative and qualitative analysis methods were used to analyze the data, and interviews were conducted with business learners to understand their experience and views on the use of English through online communication.

\subsubsection{Definition of communication unit and compound sentence in interaction}

This study uses the $\mathrm{C}$ (Communication unit) as the discourse measurement unit to divide the text corpus and analyze learners' interlanguage. Unit C adopts the definitions of Loban [20] and Mehnert [21], and includes the following discourse categories: the first category is simple sentence; The second type is the main clause with subordinate clause or embedded non subordinate structure. If the continuous sub-clause is connected by coordinate conjunctions (such as and, or, but), it is divided into different $\mathrm{C}$ units; The third type is defined as the grammatically independent Rheme Structure or the answer to a question. This kind of answer appears frequently in the dialogue and does not repeat the elements of the question. It is not an independent Rheme Structure in form, but actually completes the function of Rheme Structure. A compound sentence is a main sentence with a subordinate clause, and a complex main sentence with two or more sub-clauses.

\subsubsection{Calculation of language indicators}

This paper analyzes the learners' discourse output in each text dialogue of each period, and calculates the accuracy rate of each language index. The average value of each language index of four discourses in each period is taken to represent the learners' interlanguage of each period. The calculation methods of each language index are as follows: (1) The change of learners' interlanguage morphological accuracy rate. This paper studies the accuracy of singular and plural nouns and tense verbs in internet texts. Because of the singular and plural of nameless words and the tense 
structure of verbs in Chinese grammar system, they can be used as grammatical morphological indicators for learners' language acquisition. The correct rate of singular and plural nouns is the ratio of the correct amount of singular and plural nouns to the total amount of noun forms, and the correct rate of tenses is the ratio of the correct amount of verb tenses to the total amount of verb tenses in each text corpus. (2) The syntactic change of learners' interlanguage is studied from two aspects: $\mathrm{C}$-unit accuracy and syntactic complexity. The $\mathrm{C}$-unit accuracy is the ratio of the number of correct $\mathrm{C}$-units to the number of all $\mathrm{C}$-units, and the syntactic complexity is the ratio of the number of compound sentences to the total number of $\mathrm{C}$-units. Unit $\mathrm{C}$ in this part does not include such independent expressions as greetings, farewell and thanks, such as Hi, Hello, Friend, Yes, Yeah, No, OK, By, Thanks / Thank you and Arabic numerals.

\section{Research results and discussion}

\subsection{Research result}

Through the analysis of statistics, the correct rate of morphology and unit $\mathrm{C}$ of interlanguage has been improved, but not significantly. The accuracy of each grammatical form of interlanguage varies greatly between the first period and the second period, but it does not change significantly from the second period to the later period, and the accuracy of singular and plural forms of nouns decreases in the last stage. The syntactic complexity is low, and the frequency of compound sentences is always low, and there is no obvious change in each period. The average value of each language index of learners' corpus in four periods is shown in Table 1.

Table 1. The average of each language index of the learners' online text corpus in four periods

\begin{tabular}{|c|c|c|c|c|}
\hline Time periods & $\begin{array}{c}\text { Accuracy of singular } \\
\text { and plural nouns }\end{array}$ & $\begin{array}{c}\text { Predicate tense } \\
\text { accuracy }\end{array}$ & $\begin{array}{c}\text { Unit C } \\
\text { accuracy }\end{array}$ & $\begin{array}{c}\text { Syntactic } \\
\text { complexity }\end{array}$ \\
\hline $\begin{array}{c}\text { The first period: } \\
2018.12\end{array}$ & 0.47 & 0.50 & 0.49 & 0.14 \\
\hline $\begin{array}{c}\text { The second period: } \\
\text { 2019.09 }\end{array}$ & 0.58 & 0.71 & 0.65 & 0.09 \\
\hline $\begin{array}{c}\text { The third period: } \\
\text { 2020.03 }\end{array}$ & 0.58 & 0.63 & 0.63 & 0.11 \\
\hline $\begin{array}{c}\text { The fourth period : } \\
2020.09\end{array}$ & 0.48 & 0.68 & 0.69 & 0.12 \\
\hline
\end{tabular}

The change of singular and plural nouns is significant between the first period and the second period. With the increase of communication, learners gradually master the singular and plural forms of nouns that often sell products and time. For example, the singular and plural forms of "day, legging, shoe" and other words have no mistakes in the second period. With the expansion of communication content, the use of nouns in communication is no longer limited to the names of the products they sell. For example, "product, style, discount" and other nouns appear more frequently. Learners are uncertain about the singular and plural forms of these nouns, so the accuracy of singular and plural nouns decreases in the later stage. For example, in the fourth stage, the word "discount" appears 12 times in the text, and there is no sign of singular or plural number - there is no article or qualifier modification in front of the word, and the plural suffix is not added to the word, which significantly affects the accuracy of singular and plural numbers.

The corpus samples show that the accuracy of tenses increases significantly in the first and second periods, but does not change significantly in the last three periods. The accuracy of tense usage has been improved, but it fluctuates constantly. In the first period, the longest interactive communication was 23 rounds, but in the last three periods, the communication was more than 22 rounds, mostly more than 100 rounds. The expansion of communication content, the acceleration of communication speed and the increase of discourse turns increase the probability of language

ISSN: 0010-8189 
errors. There are four common tenses in communication: the past tense, the present tense, the present perfect tense and the future tense. They are as follows: (1) the present perfect tense has no obvious improvement in each period, and its structure is mostly the past tense of "have + verb prototype" or "have + verb", such as "have pay, have saw, have choose". (2) The present tense is the main tense in a conversation. It is often used to express past actions. The common errors in learners' corpus are: "I get your email", "Sorry I go out just now, I ship the goods, etc. (3) Generally speaking, the future tense accuracy is basically expressed by "will + verb prototype", and will be expressed by modal verb "can + verb prototype", such as "if you pay today, I can send the goods in three days". Learners can not distinguish the attitude conveyed by "can" and "will": can contains uncertain meaning to be negotiated, while "will" expresses certain future actions.

The singular and plural forms of nouns, verb tenses and syntactic structures significantly affect the accuracy of $\mathrm{C}$ unit. Although the accuracy of C-unit expression has been improved in the whole text conversation, the misuse of the singular form of nouns, the confusion of verb tenses and the negative transfer of Chinese sentence patterns have affected the significant improvement of the accuracy of C-unit expression. The negative transfer of Chinese sentence patterns is as follows: (1) The omission of subject, such as leaving "1" in the sentence "send it to your mailbox"; (2) The missing of verb "be", such as "when you free", the verb of "are" is missing; (3) Chinese way of word order, such as "no? need? send? Back" and so on. The frequency of compound sentences in the whole text is low from beginning to end, and the using frequency does not increase with the increase of communication interaction, but decreases in the later stage. The most common compound sentence patterns are the object clause with the predicate verb "think, know" and the adverbial clause with the conjunction "if, but, when, as".

\subsection{Analysis and discussion}

Corpus analysis shows that computer real-time communication, as a way of information transmission and communication, provides learners with a good communication platform, which is convenient for them to understand customers' needs and give feedback in real-time, and reach a deal in interactive negotiation. In the communication, learners sometimes directly absorb the expression of customers. For example, in the following dialogue, learners follow the language output of customers.

Case 1. Customer: you should make a vest dress like this. Student: YEAH, like this.

Case 2. Customer: can you do mixed order? Student: yeah i can do mixed order.

Case3.Customer: you have them black with grey inside fibre or black with black inside fibre?

Student: black with grey inside.

However, native and non-native English customers will ask about the meaning of learners' expression, and never give feedback on the grammatical form of learners' expression. Interactive negotiation mainly focuses on the purpose of business negotiation. In communication, the two sides constantly confirm the meaning conveyed by each other, ignoring the meaning negotiation in the form of language. For example, in case 4, learners did not use the correct tense "have sent", in case 5, learners did not use the plural form "sizes", in case 6, learners still used their own consistent wrong noun form "PC" for the second time despite the use of "PCs"

Case 4.Customer: have sent it

Student; you send?

Case 5. Customer: do all the space leggings have 2 sizes?

Student: $1: 3$ size friend

Case 6. Customer: let say 10pcs

Student: 80 for10pc

In the interactive negotiation, learners do not necessarily adopt the correct language output form of the other party, and constantly show a lack of attention to grammatical forms. This phenomenon supports Mackey, Gass \& 
McDonough [22], whose research shows that in the process of second language acquisition, although native speakers or speakers close to the target language level have a large number of correct output forms in communication, learners may not be able to adopt the correct grammatical forms in the target language.

From the online real-time communication, it is found that customers and learners do not rely entirely on English to communicate, and both sides will use websites, pictures, forms and various pictures to convey information. Due to the context support of real-time communication, although the errors of singular and plural forms of nouns and verb tenses constantly appear in communication, they do not affect trading activities. In the process of communication, both sides have a prior understanding of the conversation events. Communication and negotiation do not completely depend on the language form of communication. The scene or context supplements the missing meaning in the language information to a certain extent. The problem of language form does not lead to the interruption of communication and negotiation. Therefore, the rich online resources in online real-time communication build a communicative context with various ways and rich meanings for communication. The grammatical problems in the language do not affect customers' access to necessary information, which makes learners ignore the role of grammatical meaning in interactive negotiation language.

Due to the business transaction characteristics of network interaction, both sides of communication pay more attention to the transmission of business information. The corpus shows that the language unit $\mathrm{C}$ used by learners is usually short, similar to oral communication, and the frequency of compound sentences is very low. The research results are consistent with the students' online communication strategies in the interview, "I gradually find that we should try to use simple language to express the meaning clearly, and the other party can understand it.". Especially with the expansion of business scale and the increase of customers, the purpose of business communication makes learners pay attention to the efficiency of meaning transmission, thus increasing the use of short sentences. The "urgency" of business negotiation makes both sides of communication pay attention to the content and efficiency of language, and learners lack the motivation to correct their own language, which affects the frequency of compound sentences in communication.

Learners' attention to the target language is influenced by their own level and communicative purpose. When students are asked to evaluate their own language level during the interview, the learners say, "I think my grammar is not so good that I can express my basic ideas and the other party can understand it. That's ok.". Due to the fact that learners have made many transactions through network communication, they don't know enough about their own grammar problems, and they don't pay attention to the grammatical meaning of the output language of customers, which affects their absorption and flexible use of the correct language form of customers.

At the same time, learners often communicate with English native and non-native foreign customers in the network. The language of the other party, sometimes, is not the standard fluent native language. Some customers' output language is the interlanguage that needs to be improved. The input form in the interactive negotiation lacks consistency and accuracy. In the interview, it is said that "it is impossible to judge whether the client is an English native speaker according to the language", and the lack of English competence affects the learners' attention, imitation and absorption of the target language form. As Schmidt said, in order to acquire a new language form, learners must pay attention to the differences between their own language and the new language form, otherwise they will not be able to acquire, which will lead to language solidification for a long time [23].

Therefore, in online real-time communication, contextual features, communicative purposes, language competence and input language affect learners' attention to the grammatical meaning of second language, thus affecting the significant improvement of second language grammatical competence. On the one hand, real-time text computer communication provides a natural way to connect meaning concern with form concern. Therefore, real-time text computer communication promotes learners' grammatical accuracy between the first stage and the second stage. On the other hand, short expressions and abbreviations are widely used in text chat. Due to the time limit of real-time communication, learners cannot edit and modify their own speech [24]. The purpose and efficiency of business 
communication make the communicators have a sense of urgency in online chatting and affect their attention to the accuracy of language. Therefore, real-time text communication has different effects on different stages of learners' language development.

Blake believes that without effective instructional design, learners' second language development in computer communication can not be successful [25]. Blake thinks that when teachers combine computer communication in second language teaching, teaching methods play a greater role than computer technology in learners. When setting up the interactive negotiation activities in the foreign language learning environment, the correct use of language, the targeted language correction and the attention to the form of grammar are all indispensable important links in teaching. Otherwise, the interactive activities can't improve the language competence of the middle level students.

It can be seen that the following three aspects should be taken into consideration when improving learners' second language competence through online real-time communication in teaching. First of all, the co-construction of network communication can provide learners with communicative context, promote second language communication, improve the frequency of negotiation and interaction, and contribute to better foreign language acquisition. Second, if the instructors in the co-construction community can carry out the interactive negotiation between the form and meaning of second language output, pay more attention to various language forms in the process of communication, and improve the learners' absorption and flexible use of input, the interlanguage can make greater progress. Thirdly, the accuracy of the input language education should be guaranteed through the network interaction. Otherwise, the massive input of the other party will not promote the acquisition of grammar, which is not conducive to the development of learners' interlanguage grammar.

\section{Conclusion}

Based on learners' text-based online chatting, this study explores the development of L2 grammar of middle-level English learners in real-time computer-mediated communication. It is found that the interactive negotiation of online communication platform can improve the learners' interlanguage grammatical competence to a certain extent. The interlanguage grammar competence is significantly improved between the first two periods, and the accurate rate fluctuates in the later period, In the later stage, the improvement of grammatical competence is not significant. The research shows that the computer-mediated interactive negotiation has different effects on different stages of learners' communication. The text-based interactive communication needs to be combined with appropriate guidance in order to overcome the shortcoming that the improvement of grammatical competence is not significant in the later stages.

This study collects the real diachronic text corpus of individual computer-mediated interaction, and finds a new way for higher vocational learners to learn language in practice. The diachronic case study corpus is real and has a long time span. The research results provide a certain foundation for further exploration of computer communication in second language acquisition in the future, and provide a new direction for college students' English learning and application. The text is selected from the actual communicative corpus of learners, and the communicative time, content and emotion of communication may affect the output form of communicative language. Therefore, the results of the research and analysis have some limitations and need to be further studied with more corpus.

\section{Acknowledgements}

This research was supported by the Guangzhou Philosophy and Social Sciences Planning Office, 2021(Grant No: 2021GZGJ203).

\section{Reference}


[1] R. Ellis, X. He, "The roles of modified input and output in the incidental acquisition of word meanings," Studies in Second Language Acquisition, vol. 2, pp. 285-301, 1999.

[2] B. Smith, "Computer-mediated negotiated interaction and lexical acquisition," Studies in Second Language Acquisition, vol. 3, pp. 365-398, 2004.

[3] M. Shekary \& M. H. Tahririan, "Negotiation of meaning and noticing In text-based online chat," The Modern Language Journal, vol. 4, pp. 557-573, 2006.

[4] H. J. Zhuang, "Research on computer supported "negotiation and interaction" College English Writing Teaching," Modern educational technology, vol. 25, no. 3, pp. 89-94, 2015.

[5] J. J. Feng, Real-time computer assisted oral interaction: negotiation interaction and vocabulary acquisition, Shanghai Jiaotong University Doctoral Dissertation. 2017.

[6] D. M. Chun, "Using computer networking to facilitate the acquisition of Interactive competence," System, vol. 1, pp.173, 1994.

[7] Chao-jung Ko, "Can synchronous computer-mediated communication (CMC) help beginning level foreign language learners speak?" Computer Assisted Language Learning, vol. 3, pp. 217-236, 2012.

[8] N. Kroonerberg, "Developing communicative and thinking skills via electronic mail," TESOL Journal, no. 4, pp. 24-27, 1995.

[9] M. H.Beauvois, "Computer assisted classroom discussion in the foreign language classroom: Conversation in slow motion,” Foreign language Annals, vol. 5, pp. 455-464, 1992.

[10] M.Warschauer, "Electronic Literacies: Language, Culture, and Power in Online Education," Mahwah, NJ: L. Erlbaum Associates.1999.

[11] M. H.Beauvois, "Computer-mediated communication (CMC): Technology for improving speaking and writing," In M. Bush(ed.) 7echnlogy Enhanced Language Learning (The ACTFL Volume on Technology). Lincolnwood, IL: National Textbook Company, pp. 165-184, 1997.

[12] M. R. Salaberry, "Pedagogical design of computer mediated communication tasks: Learning objectives and technological capabilities," The modern language Journal, vol. 1, pp. 28-37, 2000.

[13] J. Pellettieri, "Negotiation in cyberspace The role of chatting in the development of grammatical Competence," In M. Warschauer \& R.Kern (eds,) Network-based Language Teaching: Concepts and Practice. Cambridge: Cambridge University Press, pp.59-86, 2000.

[14] M. H. Long, "The role of linguistic environment in second language acquisition," In W. Richie\&T. Bhatia (eds.). 1996.

[15] B. Smith, "Computer-mediated negotiated interaction: An expanded model," The Modern Language Journal, 87, pp. 38-57, 2003.

[16] S. M. Gass, "Input, Interaction, and the Second Language Learns," Mahwah, NJ: L. Erlbaum Associates. 1997.

[17] R. Ellis, "The Study of Second Language Acquisition (2nd edition," Oxford: Oxford University Press. 2008.

[18] T. Pica, "Research on negotiation: What does it reveal about second language learning conditions, processes, and outcomes?” Language learning, vol. 3, pp.493-527, 1994.

[19] M. Swain, S. Lapkin, "Problems in output and the cognitive processes they generate: A step towards second language learning,” Applied languages, vol.3, pp.371-391, 1995.

[20] D. Loban, "The Language of Elementary School Children. Champaign," IL: National Council of Teachers.1963.

[21] U. Mehnert, The effects of different lengths of time for planning on second language performance. Studies in Second Language Acquisition, vol. 20, pp. 83-108, 1998.

[22] Mackey, S. Gass, K. Mcdonough, "How do learners perceive interactive feedback?" Studies in Second Language Acquisition, vol.4, pp. 471-497, 2000.

[23] W. R. Schmidt, "Awareness and second language acquisition,” Annual review of Applied Linguistics, vol. 13, pp. 206-226, 1993.

[24] A.V.A., Muniandy, "Electronic discourse (e-discourse): Spoken, written or a new hybrid?" Prospect: An Australian Journal of TESOL, vol. 17, pp. 45-68, 2002. 
[25] C. Blake, "Potential of text-based internet chats for improving oral fluency in a second Language," The Modern Language Journal, vol. 93, pp. 227-240, 2009. 